\title{
Rivalry information acquisition and disclosure
}

Citation for published version (APA):

Li, X., \& Peeters, R. J. A. P. (2013). Rivalry information acquisition and disclosure. Maastricht University, Graduate School of Business and Economics. GSBE Research Memoranda No. 032 https://doi.org/10.26481/umagsb.2013032

Document status and date:

Published: 01/01/2013

DOI:

10.26481/umagsb.2013032

Document Version:

Publisher's PDF, also known as Version of record

\section{Please check the document version of this publication:}

- A submitted manuscript is the version of the article upon submission and before peer-review. There can be important differences between the submitted version and the official published version of record.

People interested in the research are advised to contact the author for the final version of the publication, or visit the DOI to the publisher's website.

- The final author version and the galley proof are versions of the publication after peer review.

- The final published version features the final layout of the paper including the volume, issue and page numbers.

Link to publication

\footnotetext{
General rights rights.

- You may freely distribute the URL identifying the publication in the public portal. please follow below link for the End User Agreement:

www.umlib.nl/taverne-license

Take down policy

If you believe that this document breaches copyright please contact us at:

repository@maastrichtuniversity.nl

providing details and we will investigate your claim.
}

Copyright and moral rights for the publications made accessible in the public portal are retained by the authors and/or other copyright owners and it is a condition of accessing publications that users recognise and abide by the legal requirements associated with these

- Users may download and print one copy of any publication from the public portal for the purpose of private study or research.

- You may not further distribute the material or use it for any profit-making activity or commercial gain

If the publication is distributed under the terms of Article $25 \mathrm{fa}$ of the Dutch Copyright Act, indicated by the "Taverne" license above, 


\section{Maastricht University}

Xinyu Li, Ronald Peeters

Rivalry information acquisition and disclosure

$\mathrm{RM} / 13 / 032$

\section{GSBE}

Maastricht University School of Business and Economics

Graduate School of Business and Economics

P.O Box 616

NL- 6200 MD Maastricht

The Netherlands 


\title{
Rivalry information acquisition and disclosure*
}

\author{
Xinyu $\mathrm{Li}^{\dagger} \quad$ Ronald Peeters ${ }^{\ddagger}$
}

June 20, 2013

\begin{abstract}
In the recent past there have been numerous scandals around bad practices in the food industry. Although it can be easily rationalized why these bad practices have not been reported by the inflictors themselves, it is more difficult to understand why the noninflicting competitors did not report their rivals' conspicuous acts. In this paper we study these competitors' incentives to acquire and to disclose information on the quality of their rivals' products and how regulatory intervention may enhance information disclosure. Our model involves two firms that compete in prices within a differentiated product market, where the quality of one of the firms is publicly known while that of the other firm is unknown. Before the firms set their prices, the former firm has the possibility to acquire information on the quality of the latter firm's product, and, if decided to do so, subsequently, the possibility to credibly reveal this information to the public. We find that low quality levels can be disclosed in a substitute market, but should not be expected to be disclosed in a complement market. Policies that mandate acquisition or disclosure may enhance disclosure of low quality levels, but fail to be welfare enhancing.
\end{abstract}

JEL Classification: L15, L51, D43

Keywords: strategic information disclosure, rivalry disclosure, duopoly competition.

${ }^{*}$ We like to thank Wilfried Sand-Zantman and the audiences of XXVII Jornadas de Economia Industrial (Murcia, 2012), The 61th Congress of the French Economic Association (Paris, 2012), The 9th INRA-IDEI Conference: Industrial Organization and the Food Processing Industry (Toulouse, 2012) and The 5th RGS Doctoral Conference in Economics (Duisburg, 2012) for their useful suggestions and feedback. The second author thanks the Netherlands Organisation for Scientific Research (NWO) for financial support.

${ }^{\dagger}$ Department of Economics, Maastricht University. E-mail: x.li@maastrichtuniversity.nl

${ }^{\ddagger}$ Department of Economics, Maastricht University. E-mail: r.peeters@maastrichtuniversity.nl 


\section{Introduction}

The 2008 Chinese milk scandal broke on 16 July, after sixteen infants in Gansu Province, who had been fed on milk powder, were diagnosed with kidney stones. By November 2008, China reported an estimated 300,000 victims, with six infants dying from kidney stones and other kidney damage, and a further 860 babies hospitalized. It was found that infant formula had been adulterated with the chemical melamine by some producers to cause it to appear to have a higher protein content. This issue raised concerns about food safety and political corruption in China, and damaged the reputation of China's food exports, resulting in numerous countries stopping all imports of Chinese dairy products.

Although it can be easily rationalized why the adulterating producers did not report their 'bad' practises, it is more difficult to understand why the non-adulterating competitors did not report their rivals' conspicuous acts. The first question is whether they did possess all relevant information, and if not, why not? But, in case they did know, are there any viable reasons not to publicly disclose this delicate information? May they have anticipated the bans by importing countries, which makes disclosure a self-defeating course of action? More generally, it raises the question when we can leave the information disclosure process to (the competitive pressure of) markets and when there is need for governmental intervention to protect consumers against misbehaving firms. ${ }^{1}$ In this paper we address these questions via a theoretical investigation to a firm's incentive to acquire and to disclose information on the quality of its rival's product.

In our model there are two firms competing in prices within a differentiated product market; one firm we label as incumbent, the other as entrant. We assume that the quality of the incumbent's product is publicly known (i.e., it is known by the incumbent, the entrant and all consumers) while that of the entrant is private information (i.e., it is known by the entrant, but not by the incumbent and the consumers). Before the firms set their prices, the incumbent has the possibility to acquire information on the quality of the entrant's product, and, if decided to do so, subsequently, the possibility to credibly reveal this information to the public. Neither the incumbent's information acquisition costs, nor the decision to acquire information or not, are observed by the entrant and the consumers. The realized demand for the firms depends on the (lack of) information on both firms' product qualities and the prices charged.

\footnotetext{
${ }^{1}$ For instance, in 1990, the Nutrition Labeling and Education Act was signed into United States Federal law to give authority to the Food and Drug Administration to require nutrition content labeling of most foods. From the same year onwards, the Council Directive of the European Commission strictly requires nutrition labeling to be presented in a standardized form applying throughout the Community for the benefit of the consumer and to avoid any possible technical barriers to trade.
} 
In a nutshell, we find that low quality levels may be disclosed in a market where the products can be considered substitutes, but are never disclosed in markets where products can be considered complements. Moreover, regulatory policies that implement full information acquisition and disclosure are typically welfare reducing. A policy that mandates firms to disclose information upon acquisition, while leaving the acquisition itself voluntarily without imposing additional incentives via cost subsidization, can achieve disclosure of low quality levels even in a complement market, but does not positively affect (nor negatively) ex ante overall welfare.

The remaining of the paper is organized as follows. In the next section, we shortly discuss the related literature. In Section 3 we present the details of our model of rivalry information acquisition and disclosure. In Section 4 we present the results for the situation without governmental regulation and disclosure is voluntary (and strategic). In Section 5 we introduce various regulatory instruments and assess them on the welfare that they generate (relative to the situation without regulation). Section 6 concludes.

\section{Related literature}

An important result of the early literature on strategic disclosure is the "unraveling theory"; see a.o. Akerlof (1970), Grossman (1981) and Milgrom (1981). This theory predicts a monopolist to make a full disclosure of its quality when disclosure is costless, in anticipation of consumers assuming the worst possible quality that is consistent with the available information (or lack thereof). Hence, when disclosure is costless and information is ex post verifiable at no cost (with appropriate legal litigation), there is no need for governments to step up as the free market offers enough incentive for business to disclose. ${ }^{2}$ However, as is shown by Viscusi (1978) and Jovanovic (1982), when disclosure is costly, information disclosure unravels from the top down and business only fully discloses if the quality exceeds a certain threshold (that is related to the disclosure cost).

Recently, sellers' disclosure behavior has been examined in duopoly markets by Levin, Peck and Ye (2009), Board (2009), and Hotz and Xiao (2010). Levin et al. (2009) consider a horizontal differentiation model with the firms' quality levels being private information. Before announcing their prices, at a cost, firms can publicly and truthfully disclose their own quality. In line with the results by Viscusi (1978) and Jovanovic (1982), they find that there is a threshold below which firms will not disclose their quality. ${ }^{3}$ Although there is excess

\footnotetext{
${ }^{2}$ Okuno-Fujiwara, Postlewaite and Suzumara (1990) provide fairly general conditions for complete disclosure to result in a regime of voluntary disclosure.

${ }^{3}$ The impact of competition on disclosure has already been studied in Cheong and Kim (2004). They
} 
disclosure from a welfare perspective, consumer welfare benefits from mandated disclosure. Board (2009) examines a vertical differentiation model with firms knowing their own and each others' quality level. However, they can only disclose (at no cost) their own quality level to the public. He finds that competition does not lead to full disclosure even though disclosure is costless, and it may be the case that only the high quality firm chooses to disclose. Mandatory disclosure laws can promote competition and raise consumer surplus at the expense of firm profits, potentially increasing the efficiency of the market. Hotz and Xiao (2010) consider a duopoly model where products are both horizontally and vertically differentiated with, as in Board (2009), firms knowing their own and each other's qualities, but can disclose only their own quality. Consistent with Board (2009), they find that a firm may not reveal the quality even with zero disclosure costs. The reason is that information disclosure may trigger more intense price competition and erode profits.

One assumption that the literature mentioned in the preceding two paragraphs has in common, is that sellers are a priori informed about the quality of their product. Matthews and Postlewaite (1985) study the impact of an explicit information acquisition decision on eventual information disclosure. They show that when information can be acquired at no cost and there are no disclosure rules in effect, sellers will acquire and fully disclose. However, sellers will not acquire information only if disclosure is mandatory (upon acquisition). The reason is that, opposed to a situation with voluntary subsequent disclosure, a seller can credibly claim ignorance. Building on the model introduced by Farrell and Sobel (1983) and Farrell (1986), also Shavell (1994) studies incentives to acquire product information and the effect of a mandatory disclosure rule. He finds that sellers have an excessive incentive to acquire information in the absence of a rule that mandates disclosure of available information. Again, the reason is that a seller's silence will lead to an inference by the buyer that if the seller obtained information, it must not have been favorable.

The only papers where incentives to acquire and to disclose information have been studied in a setting where sellers are in strategic conflict with other sellers, as far as our knowledge reaches, consider the information transmission process between competitors (most often about the private production costs - see Yin and Yan (2011) and the references therein) rather than that from the supply side to the demand side. Studies on incentives to disclose information on the rival's product quality to the public seems yet nonexistent.

find that full unraveling is obtained with zero disclosure cost. However, when there is a positive disclosure cost, complete concealment of information is obtained (in the symmetric equilibrium satisfying a monotonicity property on disclosure behavior) when the number of firms grows large. 


\section{The model}

We investigate a firm's incentive to acquire and to disclose information on the quality of its rival's product. Thereto, for convenience, we assume there is an incumbent (firm $I$ ) with a product of commonly and publicly known quality $\theta_{I} \in[0,1]$ that faces entrance by an entrant (firm $E$ ) with a quality $\theta_{E}$ that is drawn from the unit interval according to the uniform distribution and of which the realization is not known by the incumbent nor by the public. We assume that revelation of the entrant's quality to the public cannot credibly be done by the entrant (due to a lack of reputation) and that the incumbent would be able to disclose the entrant's quality credibly once this information is acquired of. The incumbent can acquire information on the entrant's quality via a detailed product investigation at a cost $c$ that is randomly drawn from the unit interval according to the uniform distribution of which the realization is only known by the incumbent (prior to making this information acquiring investment). Finally, the incumbent and the entrant compete in prices. ${ }^{4}$

Let the firms' individual demands be given by

$$
q_{I}=v+a \theta_{I}-b \tilde{\theta}_{E}-m p_{I}+n p_{E} \quad \text { and } \quad q_{E}=v+a \tilde{\theta}_{E}-b \theta_{I}-m p_{E}+n p_{I},
$$

where $\tilde{\theta}_{E}$ is the quality of the entrant as it is perceived (expected) by the public. The positive parameters $a, b, m$ and $n$ capture the sensitivity of the demand to quality levels and prices. So, demand increases in the own quality and decreases in that of the rival. Likewise, demand decrease in the own price and increases in that of the rival. We assume $a>b$ and $m>n$, such that "own effects" dominate "cross effects". Finally, the common value $v$ is assumed to be large enough to imply positive prices in equilibrium. ${ }^{5}$ We assume firms to produce up to demand and do not face any production cost.

In short, the game proceeds as follows. First, nature randomly chooses the entrant's quality $\theta_{E}$ (and reveals it to the entrant). Second, the incumbent decides whether to spend an amount $c$ to acquire information on the entrant's quality, where $c$ is uniformly distributed over $[0,1]$. Neither the decision, nor the cost of acquisition are observed by the entrant and the consumers. The distribution according to which this cost is drawn is common knowledge. Third, in case the incumbent has decided to acquire the information, now it has to decide whether to disclose it to the consumers or not. Fourth, both firms set their prices $p_{I}$ and $p_{E}$. Fifth, consumers observe prices, update their beliefs about the quality of the entrant's product and make their purchasing decisions.

\footnotetext{
${ }^{4}$ In this paper, we ignore the possibility that product qualities can be signalled via prices. We refer to Daughety and Reinganum (2008) for a study that unifies disclosure and signalling.

${ }^{5}$ Some sufficient conditions is provided in the appendix.
} 
The expectations that the consumers hold about the quality of the entrant's product has a negative direct effect on the the demand of the incumbent. However, as the entrant's price will be positively affected by the consumers expectations, there is a positive indirect effect on the incumbent's demand. Therefore, whether to disclose information or not, and if so, which quality levels to disclose, will depend on which of these effects dominate. The next section will deal with this in detail.

\section{Voluntary disclosure and acquisition}

In this section we study the incumbent's rivalry disclosure behavior when disclosure is voluntary. We solve the model accordingly for its subgame-perfect (Bayesian-Nash) equilibrium.

Given the incumbent's quality $\theta_{I}$ and the entrant's quality as it is perceived by consumers $\tilde{\theta}_{E}$, in equilibrium, the firms set the following prices:

$$
\begin{aligned}
& p_{I}^{*}=\frac{(2 m+n) v+(2 a m-b n) \theta_{I}+(a n-2 b m) \tilde{\theta}_{E}}{4 m^{2}-n^{2}} \\
& p_{E}^{*}=\frac{(2 m+n) v+(2 a m-b n) \tilde{\theta}_{E}+(a n-2 b m) \theta_{I}}{4 m^{2}-n^{2}} .
\end{aligned}
$$

Hence, equilibrium profits of the firms are given by:

$$
\begin{aligned}
& \pi_{I}^{*}=\frac{m\left[(2 m+n) v+(2 a m-b n) \theta_{I}+(a n-2 b m) \tilde{\theta}_{E}\right]^{2}}{\left(4 m^{2}-n^{2}\right)^{2}} \\
& \pi_{E}^{*}=\frac{m\left[(2 m+n) v+(2 a m-b n) \tilde{\theta}_{E}+(a n-2 b m) \theta_{I}\right]^{2}}{\left(4 m^{2}-n^{2}\right)^{2}} .
\end{aligned}
$$

From the incumbent's profit function, we get the following proposition.

Proposition 1. The incumbent's equilibrium profit is increasing (decreasing) in the entrant's quality as it is perceived by consumers if an-2bm is positive (negative).

This proposition identifies two different types of market structure depending on whether $a n-2 b m$ is positive or negative. In case the expression is positive, the profit of the incumbent is increasing in the rival's perceived quality and we can regard the market a "complement market"; in case the expression is negative, we can regard the market a "substitute market."

In the third stage, in case the incumbent has acquired the information about the true realization of $\theta_{E}$, the incumbent has to decide whether to disclose the available information or not. In case the incumbent decides to disclose, consumers will update their beliefs such that $\tilde{\theta}_{E}=\theta_{E}$. When consumers do not receive any information regarding the value of $\theta_{E}$, this is because either the incumbent didn't acquire the information or the incumbent did acquire the information but decided not to disclose it. Suppose that in such a case consumers update 
their belief to the value being $\theta_{E}^{*}$ (in expectation). In a complement (substitute) market, the incumbent will disclose if and only if the true value of $\theta_{E}$ is above (below) $\theta_{E}^{*}$. This level $\theta_{E}^{*}$ depends on the threshold for the acquisition cost, $c^{*}$, below which the incumbent will acquire rival information. For the complement market this $\theta_{E}^{*}$ can be implicitly formulated $\mathrm{as}^{6}$

$$
\theta_{E}^{*}=\frac{\frac{1}{2} \theta_{E}^{*} c^{*} \theta_{E}^{*}+\frac{1}{2}\left(1-c^{*}\right)}{c^{*} \theta_{E}^{*}+\left(1-c^{*}\right)}
$$

and as

$$
\theta_{E}^{*}=\frac{\frac{1}{2}\left(1+\theta_{E}^{*}\right) c^{*}\left(1-\theta_{E}^{*}\right)+\frac{1}{2}\left(1-c^{*}\right)}{c^{*}\left(1-\theta_{E}^{*}\right)+\left(1-c^{*}\right)}
$$

for the substitute market.

Since $c^{*}$ takes only values in the closed unit interval, we find that in the complement market (substitute market), $\theta_{E}^{*}$ takes values below (above) 0.5 . This means that even quality levels below (above) the level that is expected by consumers in absence of information acquisition and disclosure technologies are disclosed in case of a complement market (substitute market). In the extreme case when $c^{*}=1$ - i.e., when at any cost information is acquired (and this is understood and anticipated by consumers) - we find the "unraveling effect" of Grossman (1981), Milgrom (1981) and Milgrom and Roberts (1986), and all quality levels are disclosed for both market types.

The incumbent will only acquire information on the quality of the entrant's product, in the second stage, if the expected value of such information to the incumbent, $v_{I}$, exceeds the cost, $c$, of acquiring it. This value $v_{I}$ equals $\int_{\theta_{E}^{*}}^{1}\left[\pi_{I}^{*}\left(\theta_{I}, \theta_{E}\right)-\pi_{I}^{*}\left(\theta_{I}, \theta_{E}^{*}\right)\right] \mathrm{d} \theta_{E}$ in a complement market and $\int_{0}^{\theta_{E}^{*}}\left[\pi_{I}^{*}\left(\theta_{I}, \theta_{E}\right)-\pi_{I}^{*}\left(\theta_{I}, \theta_{E}^{*}\right)\right] \mathrm{d} \theta_{E}$ in a substitute market. The equilibrium threshold $c^{*}$ is the value of $c$ for which $v_{I}=c$. For the complement market this equation is given by

$$
c^{*}=\frac{m(a n-2 b m)\left(1-\theta_{E}^{*}\right)^{2}\left\{(2 m+n) v+(2 a m-b n) \theta_{I}+(a n-2 b m)\left[\theta_{E}^{*}+\frac{1}{3}\left(1-\theta_{E}^{*}\right)\right]\right\}}{\left(4 m^{2}-n^{2}\right)^{2}}
$$

and for the substitute market by

$$
c^{*}=\frac{m(2 b m-a n) \theta_{E}^{* 2}\left\{(2 m+n) v+(2 a m-b n) \theta_{I}-(2 b m-a n)\left[\theta_{E}^{*}-\frac{1}{3} \theta_{E}^{*}\right]\right\}}{\left(4 m^{2}-n^{2}\right)^{2}} .
$$

We can summarize the acquisition and disclosure decision of the incumbent by the following proposition (see Figure 1 for a graphical illustration).

\footnotetext{
${ }^{6}$ A quick glance at Figure 1 may be helpful to understand the right-hand side expressions.
} 
Proposition 2. (i) For the complement market, there exist thresholds $c^{*} \in[0,1]$ and $\theta_{E}^{*} \in$ $[0,0.5]$ such that information is acquired only if $c \leq c^{*}$ and disclosed only if in addition $\theta_{E} \geq \theta_{E}^{*}$. (ii) For the substitute market, there exist thresholds $c^{*} \in[0,1]$ and $\theta_{E}^{*} \in[0.5,1]$ such that information is acquired if $c \leq c^{*}$ and disclosed only if in addition $\theta_{E} \leq \theta_{E}^{*}$.

Proof. See Appendix.
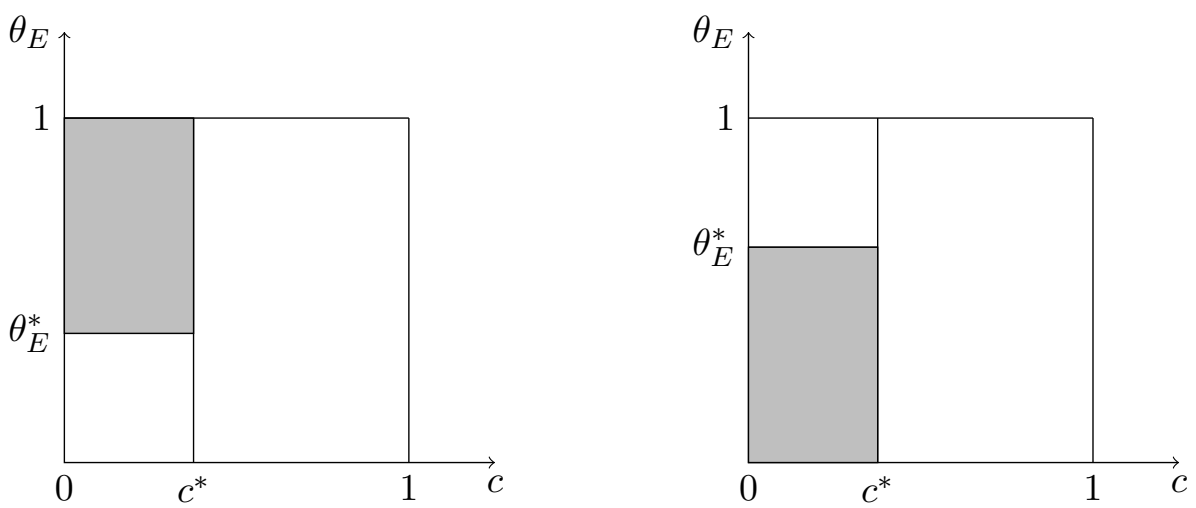

Figure 1: Information acquisition and disclosure rule of the incumbent in the complement market (left picture) and substitute market (right picture). Rivalry disclosure occurs only when the realizations of the acquisition cost and the entrant's quality combine to a point in the gray area.

Combining Equations (3) and (5) ideally would provide us with explicit solutions $\theta_{E}^{*}$ and $c^{*}$ (as functions of $\theta_{I}, a, b, m, n$ and $v$ ) for the complement market. Likewise, Equations (4) and (6) ideally would give us the explicit solutions for the substitute market. However, substitution of the latter equation in the former gives a fifth degree polynomial equation in $\theta_{E}^{*}$. As it cannot be explicitly solved, we continue with some numerical results showing how the thresholds $c^{*}$ and $\theta_{E}^{*}$ relate to incumbent's own quality $\theta_{I}$.

\section{Numerical example}

Set $v=1, a=1, b=\frac{1}{4}, m=1$. First, take $n=\frac{7}{8}$ as to consider a complement market. Solving the equilibrium thresholds $c^{*}$ and $\theta_{E}^{*}$ for different values of $\theta_{I}$ reveals that the maximum cost the incumbent is willing to spend on acquiring information on the quality of the rival's product is increasing in the quality of its own product while lower quality levels of the rival's product are disclosed at larger quality levels of the own product. So, the likelihood on information being acquired and disclosed is increasing in the quality of the incumbent's product. This comparative static property is graphically illustrated in the left panel of Figure 2. 

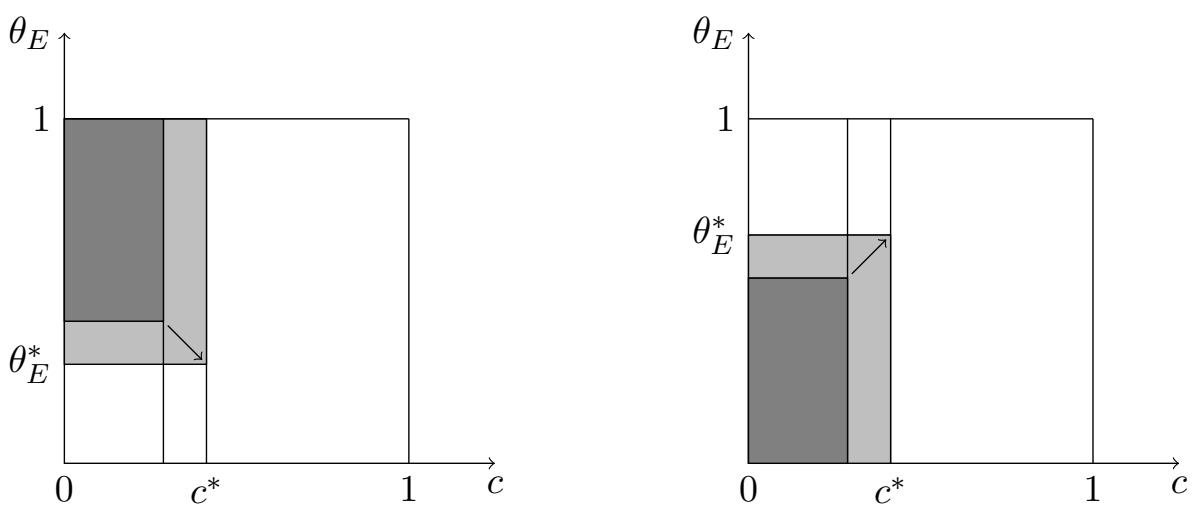

Figure 2: The area of realizations of the acquisition cost and the entrant's quality for which rivalry disclosure takes place is increasing in the incumbent's quality in the complement market (left picture) and in the substitute market (right picture).

Now, take $n=\frac{1}{8}$ as to consider a substitute market. In this case we find that, as in the complement market, the maximum cost the incumbent is willing to spend on acquiring information on the quality of the rival's product is increasing in the quality of its own product. Moreover, higher quality levels of the rival's product are disclosed at larger quality levels of the own product. As a result, like in the complement market, the likelihood on information being acquired and disclosed is increasing in the quality of the incumbent's product. This comparative static property is graphically illustrated in the right panel of Figure 2.

The fact that in the complement (substitute) market lower (higher) levels of the rival's quality are disclosed at higher quality levels of the own product may appear as a bit paradoxical as the incumbent's profit is increasing (decreasing) in the rival's quality as it is perceived by the consumers. From Equations (3) and (4) it follows that the equilibrium threshold $\theta_{E}^{*}$ at given equilibrium threshold $c^{*} \in(0,1)$ equals $\frac{\sqrt{1-c^{*}}-\left(1-c^{*}\right)}{c^{*}}$ for the complement market and $\frac{1-\sqrt{1-c^{*}}}{c^{*}}$ for the substitute market. In the former case, $\theta_{E}^{*}$ is decreasing in $c^{*}$; in the latter case, it is increasing. So, the seemingly paradoxical property can be explained by the incumbent being willing to invest more in information when it has a larger quality itself irrespective of the interaction structure of the market. As the consumers anticipate the likelihood of information being acquired being increasing in the incumbent's quality, the incumbent has to counterbalance the otherwise even more erosive impact of consumers' quality expectations on its profit via its disclosure policy. 


\section{$5 \quad$ Regulatory policies and their welfare consequences}

One finding of the previous section is that low quality levels are disclosed in a substitute market (when the costs are low), but are never disclosed in a complement market. We can identify several regulatory policies that nudge an incumbent towards more information disclosure by obligating acquisition, disclosure conditional on acquisition, or both. Furthermore, in regimes with voluntary acquisition, the cost that the incumbent incurs upon acquisition can be subsidized or not. ${ }^{7}$

First, any regime in which acquisition is mandatory implements full disclosure, as the model assumes disclosure to be costless and, hence, the unraveling theory applies. Second, the regimes with voluntary acquisition also implement full disclosure when the costs of acquisition are subsidized (by means of a reimbursement). No matter whether the subsidization is conditional on disclosure or not, it sets the incumbent's cost of acquisition virtually at zero. As the ex ante value of information is always positive (which is shown below), regardless of the market being of the complement or substitute type, the incumbent will always acquire information at zero cost. As this is known by the consumers, the unraveling theory is again applicable. Among the possible regimes considered here, only one regime remains that can be regarded non-trivial: the one with voluntary acquisition and mandatory disclosure without cost subsidization.

When disclosure is mandatory upon acquisition, but acquisition is voluntary (and not subsidized), the incumbent's decision to acquire or not is a matter of weighing the ex ante benefits of having the information against the costs of acquiring it. In case the incumbent decides not to acquire, consumers do not update their prior belief (i.e. $\tilde{\theta}_{E}=\frac{1}{2}$ ) and it receives a profit of $\pi_{I}^{*}\left(\theta_{I}, \frac{1}{2}\right)$. In case the incumbent decides to acquire the information about the quality of the entrant's product, consumers update their prior belief to the actual value (i.e. $\left.\tilde{\theta}_{E}=\theta_{E}\right)$, and the incumbent receives an expected profit of $\int_{0}^{1} \pi_{I}^{*}\left(\theta_{I}, \theta_{E}\right) \mathrm{d} \theta_{E}$. The (ex ante) value of the information is the difference between these two (expected) profit levels, and equals

$$
\tilde{v}_{I}=\int_{0}^{1} \pi_{I}^{*}\left(\theta_{I}, \theta_{E}\right) \mathrm{d} \theta_{E}-\pi_{I}^{*}\left(\theta_{I}, \frac{1}{2}\right)=\frac{m(a n-2 b m)^{2}}{12\left(4 m^{2}-n^{2}\right)^{2}} .
$$

If the costs of acquisition are below the threshold level $\tilde{c}=\tilde{v}_{I}$, the incumbent will acquire information on the quality of the entrant's product (and disclose it). Notice that $\tilde{c}$ is larger

\footnotetext{
${ }^{7}$ In January 2013, in order to get its abysmal food safety record under control, the Chinese government started offering cash rewards to people who report on others who violate food safety laws (see http://www.reuters.com/article/2013/01/15/us-china-food-safety-idUSBRE90E0H820130115). Assuming that information is always available to at least one person who does not benefit from not disclosing information, one should expect disclosure of those quality levels for which rewards are granted. In this paper, we will not dig deeper into the effectiveness and welfare implications of this particular policy instrument.
} 
than 0 and, because the value of information cannot be more than in a situation where disclosure is voluntary, $\tilde{c}$ is below the threshold $c^{*}$ of the previous section and thus below 1. Moreover, unlike in the previous section, the threshold $\tilde{c}$ does not depend on the quality of the incumbent's own product $\theta_{I}$.

The failure to solve explicitly for the threshold levels of $c^{*}$ and $\theta^{*}$ in the benchmark case without regulation hampers an explicit measurement of the impact of the regulatory policies on expected overall welfare, defined as the sum of the firms' profits (based on the esteemed quality levels) and the consumers surplus (calculated on basis of the true quality levels) with the cost of information acquisition subtracted. Therefore we continue, again, with a numerical analysis.

\section{Numerical example}

Again, we set $v=1, a=1, b=\frac{1}{4}, m=1$. Figure 3 shows for the range of values of $n$ between 0 and 1 , the welfare that is generated in each of the three possible scenarios: (1) the benchmark situation without regulation (dotted curve), (2) the regimes that induce full acquisition and disclosure (solid curve), and (3) the regime with voluntary acquisition and mandatory disclosure without cost subsidization (dashed curve). Notice that for values of $n$ below 0.5 the market is of the substitute type, while for values of $n$ above 0.5 the market is of the complement type.

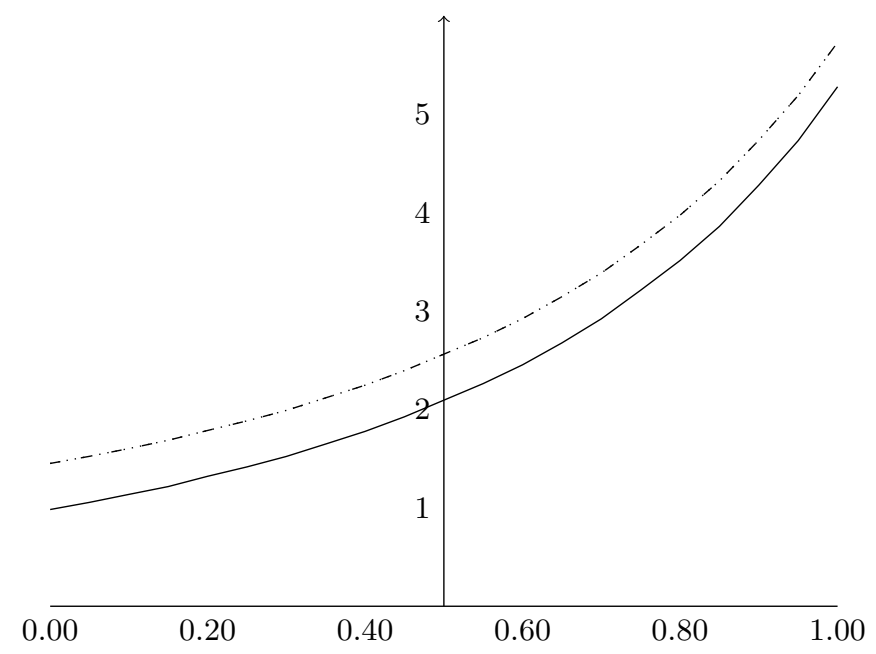

Figure 3: Welfare in the different scenarios as a function of market type.

It is clear from the figure that a regime that implements full disclosure negatively affects welfare (for all market types). The reason is of course that the benefit of the information does not exceed the cost of the information being acquired - a clear overinvestment information. 
What is less visible from the figure is the impact of the voluntary acquisition and mandatory disclosure policy on welfare. Here, the curve matches closely with that of the benchmark situation. In order to identify a possible difference, for the values of $n$ with stepsize 0.05 , we numerically computed the welfare twenty times on basis of thousand random draws for $\theta_{I}, \theta_{E}$ and $c$. This generates for each value of $n$ twenty approximations of the welfare for either regime. Next, for each value of $n$, we run a Mann-Whitney test to contest equality of welfare levels on basis of the two sequences of twenty approximation. All $p$-values (one for each value of $n$ ) are in the range $[0.79,0.99]$. So, we cannot reject equality of the generated welfare levels, and hence, we cannot conclude that a policy with voluntary acquisition and mandatory disclosure has any effect on welfare, neither positively nor negatively.

\section{Conclusion}

In this paper we study, by means of a duopoly model, the incentives of businesses to acquire and disclose information on their rivals' product qualities. This helps us to understand when we can leave the information disclosure process to (the competitive pressure of) markets and when there is need for governmental intervention to protect consumers against misbehaving firms. We find that low quality levels may be disclosed in a substitute market (when the costs are low), but are never disclosed in a complement market. Moreover, regulatory policies that implement full information acquisition and disclosure are typically welfare reducing. A policy that mandates firms to disclose information upon acquisition, while leaving the acquisition itself voluntarily without imposing additional incentives via cost subsidization, can achieve disclosure of low quality levels even in a complement market (when the acquisition costs are not too high), though does not positively affect (nor negatively) ex ante overall welfare.

\section{References}

1. Akerlof GA (1970). The market for "lemons": Qualitative uncertainty and the market mechanism. The Quarterly Journal of Economics 84(3): 488-500.

2. Board O (2009). Competition and disclosure. The Journal of Industrial Economics 57(1): 197-215.

3. Cheong I and J-Y Kim (2004). Costly information disclosure in oligopoly. The Journal of Industrial Economics 52(1): 121-132.

4. Daughety AF and JF Reinganum (2008). A unified model of disclosure and signalling. The RAND Journal of Economics 39(4): 971-989. 
5. Farrell J (1986). Voluntary disclosure: Robustness of the unraveling result, and comments on its importance. In: RE Grieson (ed.) Antitrust and Regulation. Lexington Books.

6. Farrell J and J Sobel (1983). Voluntary disclosure of information. Unpublished notes.

7. Grossman SJ (1981). The informational role of warranties and private disclosure about product quality. The Journal of Law and Economics 24(3): 461-483.

8. Hotz VJ and M Xiao (2010). Strategic information disclosure: The case of multiattribute products with heterogeneous consumers. Working paper.

9. Jovanovic B (1982). Truthful disclosure of information. The Bell Journal of Economics 13(1): $36-44$.

10. Levin D, J Peck and L Ye (2009). Quality disclosure and competition. The Journal of Industrial Economics 57(1): 167-196.

11. Matthews S and A Postlewaite (1985). Quality testing and disclosure. The RAND Journal of Economics 16(3): 328-340.

12. Milgrom PR (1981). Good news and bad news: Representation theorems and applications. The Bell Journal of Economics 12(2): 380-391.

13. Milgrom PR and J Roberts (1986). Relying on the information of interested parties. The RAND Journal of Economics 17(1): 18-32.

14. Okuno-Fujiwara M, A Postlewaite and K Suzumara (1990). Strategic information revelation. The Review of Economic Studies 57(1): 25-47.

15. Shavell S (1994). Acquisition and disclosure of information prior to sale. The RAND Journal of Economics 25(1): 20-36

16. Viscusi WK (1978). A note on "lemons" markets with quality certification. The Bell Journal of Economics 9(1): 277-279.

17. Yin X and J Yan (2011). Information acquisition and disclosure: The case of differentiated good duopoly. Working paper. 


\section{A Proofs}

(i) Complement market. Equation (3) can be rewritten as

$$
c^{*}=\frac{1-2 \theta_{E}^{*}}{\left(1-\theta_{E}^{*}\right)^{2}} .
$$

Let us denote the right-hand side of this equation by $F\left(\theta_{E}^{*}\right)$ and denote the right-hand side of Equation (5) by $G\left(\theta_{E}^{*}\right)$. Since $a>b>0, m>n>0, a n-2 b m>0$ and $v$ is sufficiently large to guarantee positive prices, the first derivatives of $F$ and $G$ are both negative on the interval $(0,1)$. Moreover, since $F(0)=1$ and $F(0.5)=0$ and $G(1)=0$, the condition $G(0) \leq 1$ guarantees at least one solution of $F=G$ in the interval $[0,0.5] .{ }^{8}$ Equation (7) implies that such a solution gives rise to a $c^{*}$ in $[0,1]$.

In terms of restrictions on $v$, for given value of $\theta_{I}, G(0) \leq 1$ is equivalent to

$$
v \leq \frac{\left(4 m^{2}-n^{2}\right)^{2}-m(a n-2 b m)\left[(2 a m-b n) \theta_{I}+\frac{1}{3}(a n-2 b m)\right]}{m(2 m+n)(a n-2 b m)} .
$$

To ensure that this is satisfied for all values of $\theta_{I}$, it requires

$$
v \leq \frac{\left(4 m^{2}-n^{2}\right)(2 m-n)}{m(a n-2 b m)}-\frac{(2 a m-b n)+\frac{1}{3}(a n-2 b m)}{(2 m+n)} .
$$

A sufficient condition for the prices to be positive is

$$
v \geq 0
$$

(ii) Substitute market. Equation (4) can be rewritten as

$$
c^{*}=\frac{2 \theta_{E}^{*}-1}{\theta_{E}^{* 2}} .
$$

Let us denote the right-hand side of this equation by $F\left(\theta_{E}^{*}\right)$ and denote the right-hand side of Equation (6) by $G\left(\theta_{E}^{*}\right)$. Since $a>b>0, m>n>0,2 b m-a n>0$ and $v$ is sufficiently large to guarantee positive prices, the first derivatives of $F$ is positive on the interval $(0,1)$. Moreover, if $v \geq \frac{(2 b m-a n)+(2 a m-b n) \theta_{I}}{(2 m+n)}$, then also the first derivative of $G$ is positive on the interval $(0,1)$. Moreover, since $F(0.5)=0$ and $F(1)=1$ and $G(0)=0$, the condition $G(1) \leq 1$ guarantees at least one solution of $F=G$ in the interval $[0.5,1]$. Equation (8) then implies that such a solution gives rise to a $c^{*}$ in $[0,1]$. In terms of restrictions on $v$, for given value of $\theta_{I}, G(1) \leq 1$ is equivalent to

$$
v \leq \frac{\left(4 m^{2}-n^{2}\right)^{2}-m(2 b m-a n)\left[(2 a m-b n) \theta_{I}-\frac{2}{3}(2 b m-a n)\right]}{m(2 m+n)(2 b m-a n)} .
$$

\footnotetext{
${ }^{8}$ Notice that it only provides a sufficient condition.
} 
To ensure that this is satisfied for all values of $\theta_{I}$, it requires

$$
v \leq \frac{\left(4 m^{2}-n^{2}\right)(2 m-n)}{m(2 b m-a n)}-\frac{(2 a m-b n)-\frac{2}{3}(2 b m-a n)}{(2 m+n)} .
$$

A sufficient condition for the prices to be positive is

$$
v \geq \frac{(2 b m-a n)}{(2 m+n)} .
$$

